\title{
REVIEW
}

\section{HYPERIMMUNE GLOBULIN AND MONOCLONAL ANTIBODY FOR THE TREATMENT OF SARS COV-2 INFECTION}

Oswaldo Jesus Rodrigues da Motta ${ }^{1,2}$, Andréia Patrícia Gomes ${ }^{1}$, Leandro Almeida de Oliveira ${ }^{3}$, Leonardo de Almeida Oliveira ${ }^{3}$, Caio Henrique Santos Almeida $^{4}$ and Luciene Muniz Braga ${ }^{1}$

\section{ABSTRACT}

The current pandemic of COVID-19 (Coronavirus Disease-19), caused by the pathogen SARSCoV-2, leading to thousands of deaths in 2020, has mobilized the scientific community, with the purpose of understanding the different aspects of the disease and proposing new treatment and prevention measures. Research carried out in several areas includes evaluating the possibility of using hyperimmune globulin and monoclonal antibodies against SARS CoV-2 as well as analyzing the viability and efficacy of monoclonal antibodies and hyperimmune globulin in combating Sars-CoV-2. A literature review was carried out with a defined search strategy using the keywords (i) "hyperimmune globulin", (ii) "monoclonal antibody", (iii)" covid-19" and (iv)" sars-cov-2", in the PubMed and ResearchGate databases, using the bibliographic references of the articles selected in these databases. Of the 187 citations obtained, 10 articles published between 2019 and 2020 were selected after reading the summary of each one and determining its compatibility with the objective of this study. Final considerations highlight the main challenges and the feasibility of using hyperimmune globulin and monoclonal antibodies for the treatment/prevention of SARS CoV-2 infection.

KEY WORDS: Hyperimmune globulin; monoclonal antibody; COVID-19; SARS-CoV-2.

\section{INTRODUCTION}

SARS CoV-2 is a virus belonging to a large family of coronaviruses capable of infecting both humans and animals. The first coronavirus was discovered in the 1960s in the respiratory tract of adults and causes a common cold (Hamre \& Procknow, 1966).

\footnotetext{
1. Universidade Federal de Viçosa (UFV). Department of Medicine and Nursing. Viçosa, Minas Gerais, Brazil.

2. Università degli Studi di Torino. Department of Public Health Sciences and Pediatrics. Turin, Italy.

3. Faculdade Dinâmica (FADIP). Graduating in Medicine. Ponte Nova, Minas Gerais, Brazil.

4. Universidade Federal de São João del-Rei (UFSJ). Graduating in Medicine. São João del-Rei, Minas Gerais, Brazil.
}

Corresponding author: Oswaldo Jesus Rodrigues da Motta. Av. Peter Henry Rolfs, s / n Campus Universitário, Viçosa - MG, 36570900, Brazil. Email: oswaldo.motta@ufv.br 
In the same decade, several discoveries regarding pathogens similar to B814 occurred. As these were eter sensitive, scientists stated that the virus needed a lipid coating to promote infection. This group was called "OC - Organ Culture" since it was how the virus was able to replicate in the laboratory. Through electronic microscopy, Almeida \& Tyrrell (1967) showed that all the viruses that were being investigated had a similar morphology, including other viruses of animal origin also being researched, with crown shaped surface projections, thus naming the group coronavirus, which was later officially recognized as a new genus of viruses (Kahn \& McIntosh, 2005).

The first serious outbreak of coronavirus occurred between 2002 and 2003, quickly leading to acute respiratory failure syndrome (severe acute respiratory syndrome) and was named SARS-CoV. According to the United States Centers for Disease Control and Prevention (CDC, 2004), this strain has been reported in 29 countries in Asia, North America and South America, with approximately 8,098 infected and 774 deaths. More cases were documented in April 2004 (Guan et al., 2003).

In 2012, in Saudi Arabia, a new strain of coronavirus was identified and spread to the Middle East, Africa and Europe, the disease was named Middle East Respiratory Syndrome (Middle East Respiratory Syndrome MERS-CoV). In 2015, the same strain was identified in South Korea after a traveler returned from the Middle East, leaving nearly 200 infected and 36 dead. Since 2012, a total of 2,494 cases and 858 deaths have been confirmed in 27 countries. The mortality rate of MERS-CoV according to these data was approximately $35 \%$ in that period (WHO, 2020a).

Currently, the world is going through its worst health crisis in decades, the COVID-19 pandemic, caused by the SARS-CoV-2 strain that has shown to be highly virulent and potentially lethal. COVID-19 was first reported in China, specifically in Wuhan, the capital of Hubei, in December 2019 and has already infected almost nine million people, with approximately 500,000 deaths reported worldwide in the first six months of the disease.

The etiology of SARS-CoV-2 remains unknown to date. A study published in Nature journal by Andersen et al. (2020) proposes two hypotheses for the emergence of the virus: 1) The mutation of a coronavirus strain in a host animal before transfer to humans. 2) Natural selection in humans after zoonotic transmission. The hypothesis of a possible inadvertent leak from laboratories that carried out research with the virus has practically been ruled out.

Clinically, the disease progresses with respiratory symptoms of varying intensity, simulating a cold or even evolving to severe respiratory failure, while in some cases, the patient can be asymptomatic. In most cases, the patient has fever, fatigue and a dry cough. Other symptoms include sputum production, anorexia, myalgia, dyspnea, hypoxemia, gastrointestinal disorders, among others (WHO, 2020b). 
The need for effective treatment for SARS-CoV-2 is vital to stop the pandemic and reduce possible sequelae, morbidity and mortality. Studies have been performed worldwide with a view to implementing possible curative and preventive therapies. Laboratory studies have demonstrated a possible destruction of the pathogen by various pre-existing drugs, including biological drugs such as hyperimmune globulin and monoclonal antibodies, which are among the main and most promising therapies with excellent results in culture media (Buonaguro et al., 2020, Shanmugaraj et al., 2020).

In view of the possibility of hyperimmune globulin and monoclonal antibodies being promising drugs for the treatment of COVID-19, this review aims to analyze the viability and efficacy of monoclonal antibodies and hyperimmune globulin in combating Sars-CoV-2.

The logic is simple to understand: antibodies developed by patients who recover from COVID-19 can be transferred from one individual to another, thus, if it is possible to transfer antibodies from a cured individual to an infected individual, it may be possible to combat the pathogen that is still active in the infected organism.

\section{METHODS}

The literature review was carried out by consulting PubMed (US National Library of Medicine) and ResearchGate databases through May and June 2020. The terms researched were defined according to the Health Sciences Descriptors (Decs), based on four search strategies: (i) "hyperimmune globulin and COVID-19"; (ii) "hyperimmune globulin and SARS-CoV-2"; (iii) "monoclonal antibody and "COVID-19"; (iv) "monoclonal antibody and "SARS-COV-2".

In addition to research in the databases, the bibliographic references of the articles selected in them were utilized. Inclusion criteria: studies published on SARS-CoV-2 in 2019 and 2020, in Spanish, English and Portuguese, OpenAcess. The research resulted in 187 publications (Table 1), with 10 articles selected that responded to the objectives of this review, 4 of which used the literature review method, 3 the perspective and 3 the clinical trial. Below, Table 2 and flowchart summarizes the ten related articles according to the respective problems addressed, identification and study categories. 
Table 1. Search results in PubMed and ResearchGate repositories.

\begin{tabular}{|l|c|c|}
\hline Term Researched & PubMED & ResearchGate \\
\hline "hyperimmune globulin and COVID-19" & 01 & 04 \\
\hline "hyperimmune globulin and SARS-CoV-2" & 01 & 03 \\
\hline "monoclonal antibody and COVID-19" & 53 & 25 \\
\hline "monoclonal antibody and "SARS-CoV-2" & 42 & 58 \\
\hline TOTAL & 97 & 90 \\
\hline
\end{tabular}

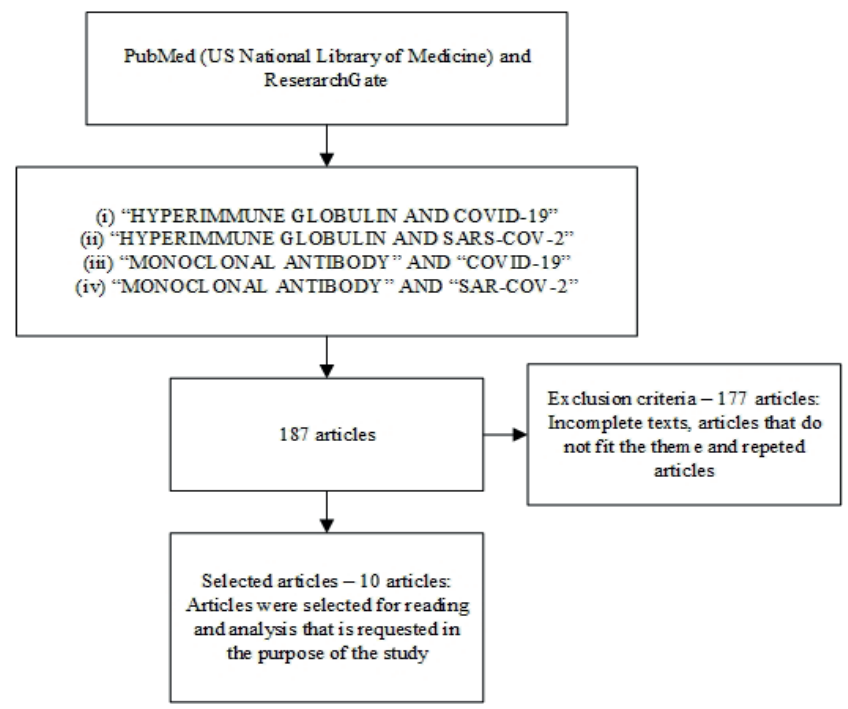

Figure. Flowchart 


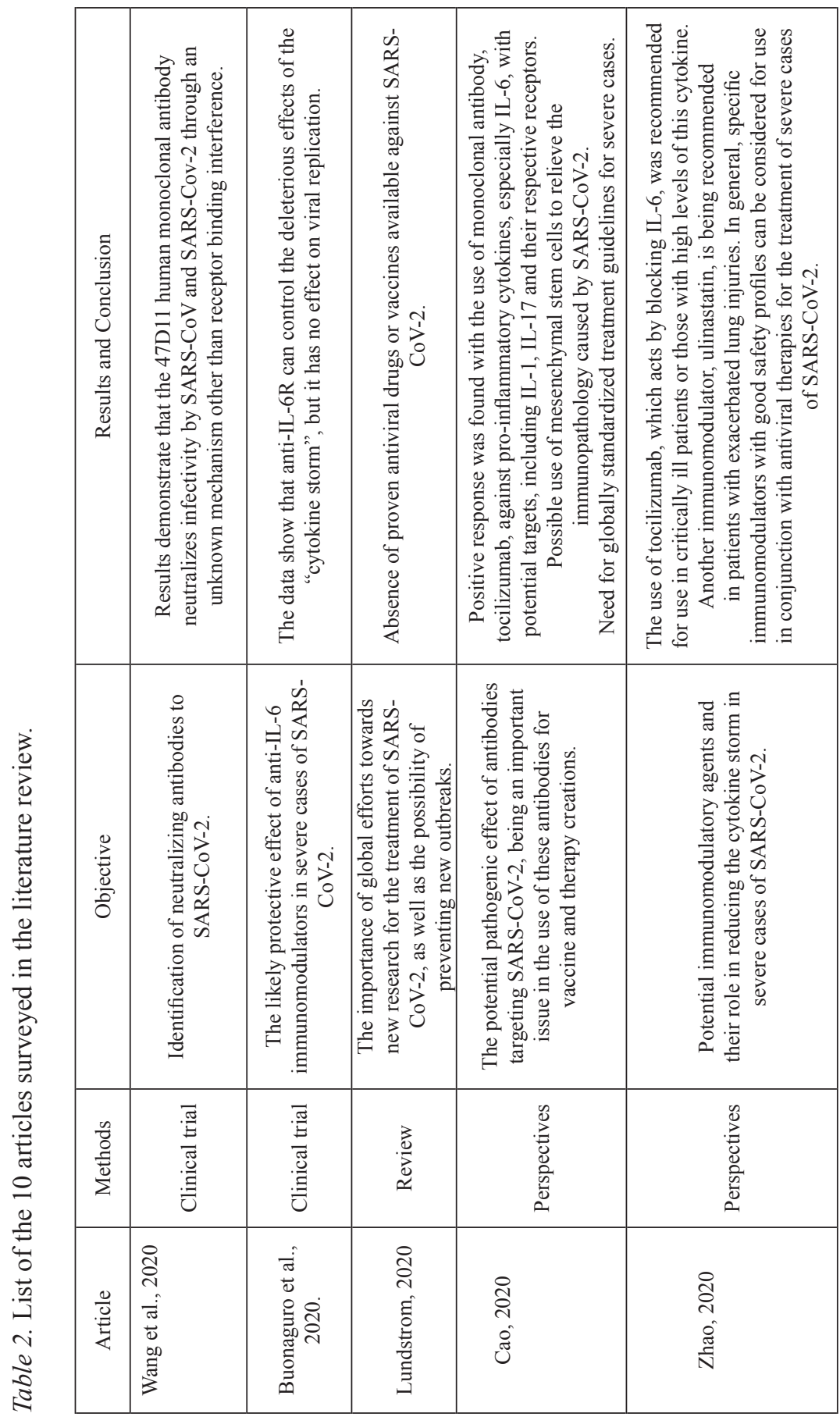




\begin{tabular}{|c|c|c|}
\hline 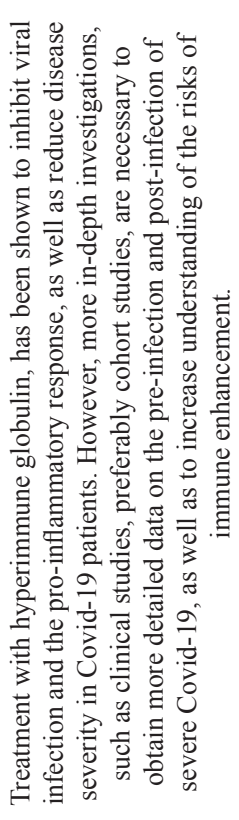 & 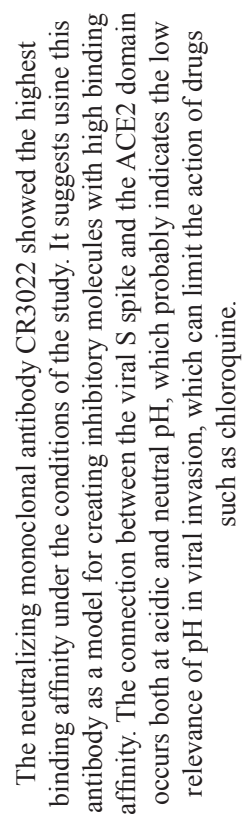 & 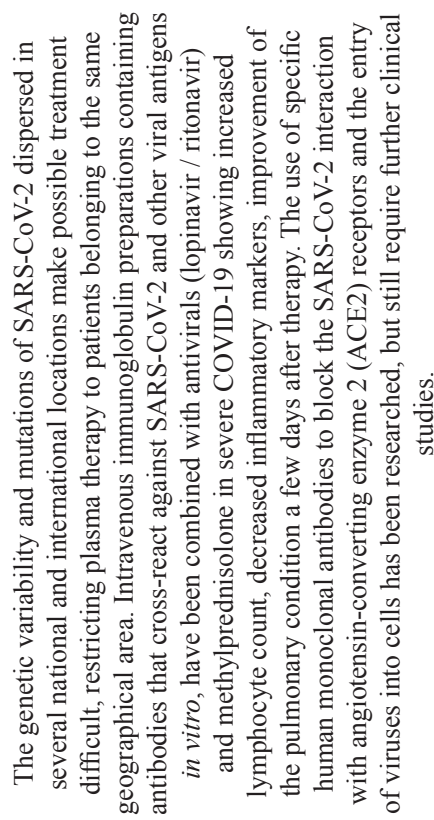 \\
\hline 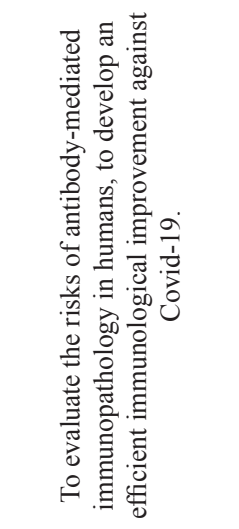 & 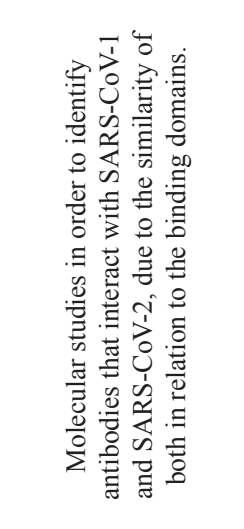 & 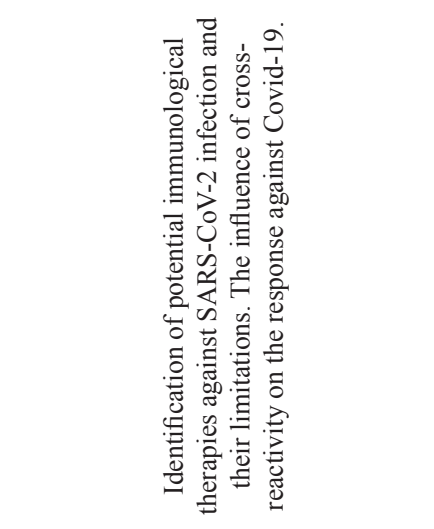 \\
\hline$\frac{3}{\frac{3}{2}}$ & 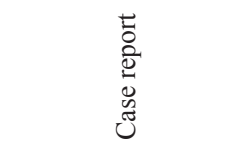 & $\frac{3}{0}$ \\
\hline 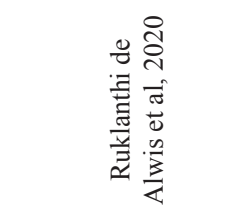 & 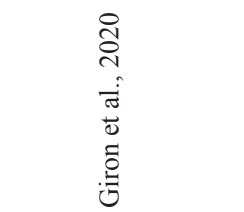 & 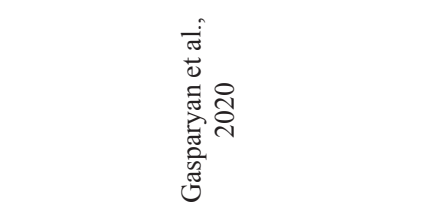 \\
\hline
\end{tabular}




\begin{tabular}{|c|c|}
\hline 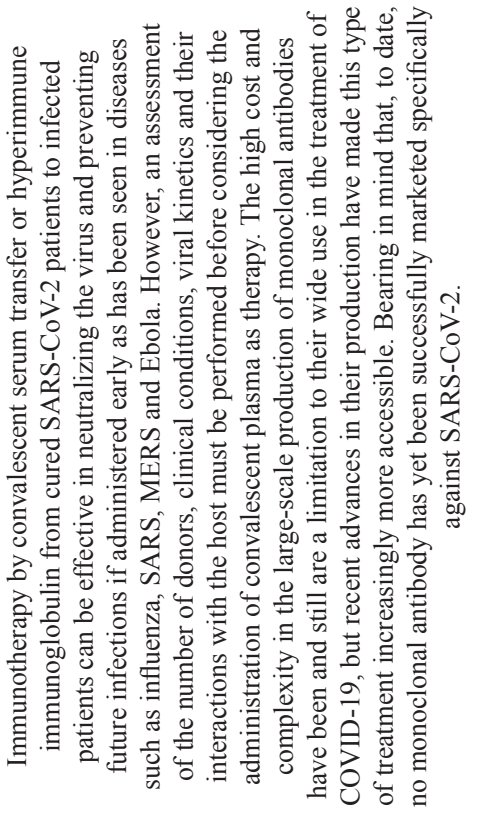 & 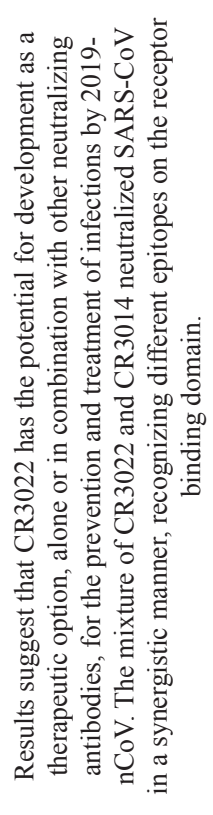 \\
\hline 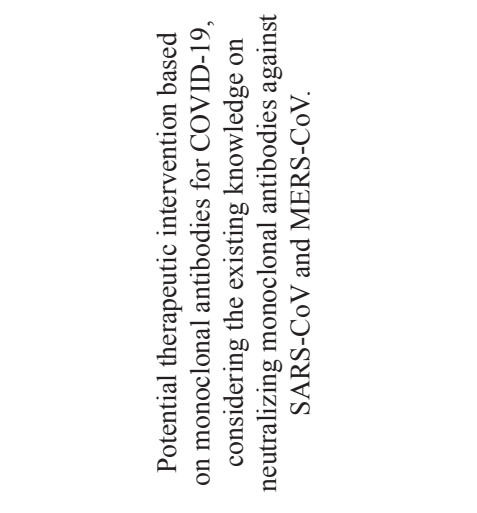 & 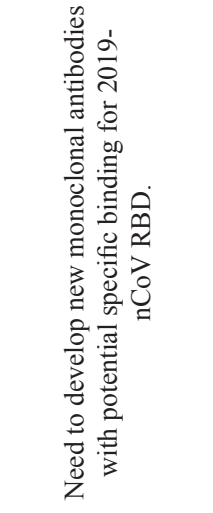 \\
\hline$\frac{\sqrt[3]{0}}{2}$ & 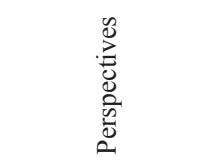 \\
\hline 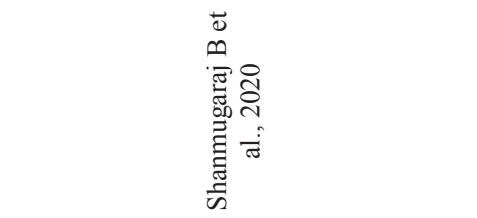 & 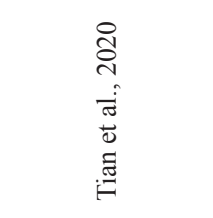 \\
\hline
\end{tabular}




\section{DISCUSSION}

Antiviral drugs (lopinavir, ritonavir, umifenovir), antiparasitic drugs (ivermectin and nitazoxanide) and immunomodulators (chloroquine / hydroxychloroquine associated with azithromycin and / or zinc) are being clinically tested, but have not yet demonstrated, with sufficient evidence, their superiority when compared to conventional treatment (Shaffer, 2020; Zhao et al., 2020). In addition to chemical substances, researchers are testing highly specific immunobiological drugs in the laboratory to combat COVID-19.

Although some of the surveyed studies described other types of treatment, such as those mentioned above, in this review, we will discuss only immunobiologicals, namely, monoclonal antibodies (mAbs) and hyperimmune globulins. Hyperimmune globulin is the concentration of antibodies obtained from the plasma of people who become infected with a certain pathogen and develop immunity naturally. As each organism is different, the antibodies obtained from one person may work differently in another, having other attack sites (Savoy, 2018).

Unlike hyperimmune globulin, monoclonal antibodies used in therapies are generally synthesized in laboratories based on the analysis of the target molecule; for this reason, they are highly specific. They represent the largest class of immunobiologicals capable of promoting passive immunotherapy against viral infections. The use of these antibodies signals a new era in the treatment and prevention of infectious diseases with high specificity, purity and insurance with low risk of blood contamination. Many monoclonal antibodies have been developed in recent years. (Savoy, 2018)

Since the SARS-CoV outbreak in 2002-2003, numerous approaches have been used to develop therapeutic agents and vaccines for coronaviruses, the main three of which are application of a broad spectrum of existing antiviral drugs, screening chemical libraries containing many existing compounds or databases and developing new specific drugs based on the genome and biophysical understanding of individual coronaviruses.

Giron et. al (2020) argue that SARS-CoV-2 like SARS-CoV-1 has spine-like type I glycoproteins covering its entire outer surface, characterizing it as a type of coronavirus. These glycoproteins may be the key to discovering new treatments and vaccines. The evaluation of the similarity between SARSCoV-1 binding receptor (RBD) and SARS-CoV-2 was the first strategy used to try to locate an antibody against the latest virus, considering that SARS-CoV-1 receptors had been better studied before the pandemic. However, preliminary studies have shown that antibodies that bind to SARS-CoV-1 receptors do not interact with SARS-CoV-2, increasing the challenge even more. 
Despite the divergence, the COVID-19 binding receptor is located on protein $\mathrm{S}$ and binds to the host cell surface as if it were an angiotensinconverting enzyme (ACE-2), similar to SARS-CoV-1. Recent studies have also shown that the RBDs of COVID-19 have a strong connection with angiotensin-converting enzyme 2 (ACE-2), which may be a pathway used to create future therapies (Giron et al., 2020)

From this information, the virus could be prevented from entering the cells by inhibiting its binding with an anti-ACE-2 monoclonal antibody and viral protease inhibitors. The use of these monoclonal antibodies against SARS-CoV-1 and MERS-CoV surface proteins has shown promise in vitro and in vivo, which evidences their great potential against SARS-CoV-2 (Shanmugaraj et al., 2020).

Corroborating the genetic analysis of the new coronavirus, Gasparyan et al. (2020) noted that specimens of SARS-CoV-2 with distinct genetic characteristics have already been reported, with two subtypes ( $\mathrm{L}$ and $\mathrm{S}$ ) and more than 140 mutation points, making it highly contagious and rapidly spreading. Four main proteins in the structure of SARS-CoV-2 are responsible for human cell interaction and intracellular replication: membrane proteins $(\mathrm{M})$, envelope (E), nucleocapsid (N) and spike (S). It is speculated that there are epitopes resistant to mutations in the genes that encode $\mathrm{S}$ and $\mathrm{N}$ proteins that can be identified in experimental vaccine models and directed by antibodies.

Shanmugaraj et al. (2020) argue that passive immunization with antibodies that can recognize epitopes of the virus can reduce its replication and severity. These antibodies can be isolated from the blood of previously infected patients who are already cured of COVID-19, or replicated in the laboratory. Immunotherapy by convalescent serum transfer or hyperimmune immunoglobulin from cured SARS-CoV-2 patients to infected patients can be effective in neutralizing the virus and preventing future infections if administered early, as has been seen in diseases such as influenza, SARS, MERS and Ebola. However, assessment must be conducted regarding the number of donors, clinical conditions, viral kinetics and their interactions with the host before considering the administration of convalescent plasma as therapy.

The use of specific human monoclonal antibodies to block the SARS$\mathrm{CoV}-2$ interaction with angiotensin-converting enzyme 2 (ACE2) receptors may prevent the virus from entering cells. To this end, plasma B lymphocytes are collected from patients who recovered from COVID-19, but it is difficult to identify and standardize specific antibodies. One of the initial in vitro studies that aimed to clone mAbs reported high titers of IgG antibodies against the spike SARS-CoV-2 spike (S) 1 subunit of the surface protein and its receptor binding site in most recovered patients. A small fraction of these antibodies potently blocks interaction with ECA2. The results of collecting these blocking mAbs using human B cells are promising, although no clinical trial has been 
found in the literature to assess the effectiveness of the method and to explore the risk of adverse effects, such as acute transfusion-related lung injury (Gasparyan et al., 2020).

The genetic variability and mutations of SARS-CoV-2 dispersed in several national and international locations also make it difficult to use this method for treatment, restricting plasma transfusion therapy only to patients belonging to the same geographical area. Another major limitation, in addition to the high cost of treatment with convalescent plasma, is that in all the series of reported cases, there are no patients as control cases not receiving antibody therapy (Gasparyan et al., 2020).

In the laboratory, simulations were carried out at constant $\mathrm{pH}$ to evaluate the formation of complexes between the RBDs of SARS-CoV-1 and SARS-CoV-2 and fragments obtained from monoclonal antibodies (mAbs) 80R, CR3022, m396 and F26G29, measuring their affinities, in addition to quantifying and titrating the amino acids involved in these interactions. From the analysis, a method of recognition of electrostatic epitopes will be applied using biological computational simulation, more specifically the method known as Monte Carlo to identify the differences and similarities between the complexes formed and map their origin and possible biological implications (Giron et al., 2020).

The theoretical study confirmed that both SARS-CoV-1 and SARS$\mathrm{CoV}-2$ have a similar affinity to ACE-2 and that affinity was not altered by $\mathrm{pH}$ similarity in neutral and acidic $\mathrm{pH}$; therefore, drugs that act in the alteration of cell $\mathrm{pH}$, such as chloroquine, may not be effective. The only monoclonal antibody with an affinity for the SARS-CoV-2 RBD was CR3022. The study also showed that the affinity between SARS-CoV-2 and ACE is greater than that of its predecessor (SARS-CoV-1), making it difficult to block it by means of monoclonal antibodies (Giron et al., 2020).

To solve this problem, the study found three amino acids which, if substituted by CR3022, can increase its affinity for the SARS-CoV-2 RBD. Such results can contribute to the development of new diagnostic methods, treatments or even vaccines against COVID-19 (Giron et al., 2020).

Another treatment approach, especially in critically ill patients, is the use of monoclonal antibodies against inflammatory cytokines. In patients with pneumonia due to SARS-CoV-2, there is a characteristic immune response with an exaggerated increase in IL-6 and other inflammatory components, such as IL-12 and TNF-alpha, which can lead to cytokine release syndrome (CRS), an intense and acute inflammatory response causing tissue damage, mainly in the cardiac, hepatic, renal and pulmonary tissues, related to a worsening of the clinical picture, such as respiratory failure, shock or multiple organ dysfunction. increasing the mortality of these patients (Cao, 2020). 
Based on this information, a preliminary study by Fu et al. with 21 patients infected with SARS-CoV-2 presenting moderate to severe clinical pictures received one or two doses of the anti-IL6 antibody tocilizumab $(400 \mathrm{mg}$ / dose) along with other therapies, such as lopinavir and methylprednisolone. The majority improved with a decrease in the need for oxygen $(15 / 21,75 \%)$, a decrease in CRP and an increase in lymphocyte levels. Two patients were removed from the mechanical ventilator in less than 5 days of tocilizumab treatment.

In this context, in May this year, tocilizumab was added to the 7th edition of therapies recommended for COVID-19 by the National Health Commission of China for critically ill patients, with high levels of IL-6 and extensive bilateral lung injuries. Limited studies in Italy that tested the drug claimed to have had better results in non-intubated patients who had high levels of IL6, CRP, ferritin and LDH.

The combined use of an immunobiological agent to reduce the cytokine storm can give doctors more time to provide supportive treatment for patients with COVID-19. Anti-IL6 antibodies can act to control the "cytokine storm" during viral replication but with no direct effect against the virus (Buonaguro et al., 2020).

In the USA, another IL-6 inhibitory antibody, sarilumab, has been tested in patients with severe forms of COVID-19. The CRS of the virus infection resembles that of cancer patients treated with CAR-T. In this case, tocilizumab proved effective against CRS and was approved by the FDA in 2017. More studies are being conducted to prove the same effectiveness in fighting the CRS of COVID-19, meanwhile it is possible to speculate that drug inhibition of cytokines may prevent an exaggerated inflammatory response with infiltration of monocytes/macrophages in the lungs, causing severe damage to the organ and extreme increases in inflammatory cytokines such as IL1, IL-6, IL-8, CXCL-10 and MCP-1, which can cause a large vascular leak and even death (Buonaguro et al., 2020). On 8/23/2020 the US Food and Drug Administration issued an emergency use authorization for experimental convalescent plasma for the treatment of COVID-19 in hospitalized patients (Li et al., 2020; Gharbharan et al., 2020).

\section{FINAL CONSIDERATIONS}

For effective disease prevention, the combination of different monoclonal antibodies, which recognize different epitopes on the viral surface, can estimate a wide range of neutralization forms, including possible mutant proteins, which are the best options for passive immunotherapy. The monoclonal antibodies cocktail may present potent antiviral activity that would increase the effectiveness of treatment and prevent viral escape (which renders the response of antibodies present in the human body during infection 
inefficient). However, the large-scale production of monoclonal antibodies is laborious, expensive and time-consuming, hindering current use. However, recent advances in therapeutic protein production platforms could lower the cost and make these more accessible. As for monoclonal antibodies, the Phase 3 sarilumab study in COVID-19 patients was suspended since it did not meet their primary and secondary outcomes, when added to the best supportive treatment compared to the best supportive treatment alone (placebo), including in a second cohort of patients who received a higher dose, issued on July 2, 2020 by Sanofi and Regeneron Pharmaceuticals, Inc. Subsequently, on July 29, 2020, Roche announced that the phase III COVACTA study by Actemra ${ }^{\circledR}$ / RoActemra ${ }^{\circledR}$ (tocilizumab) did not achieve its primary goal of improving the clinical status in adult hospitalized patients with severe COVID-19-associated pneumonia; in addition, the main secondary outcomes, which included the difference in patient mortality at week four, were not met.

\section{CONFLICTS OF INTEREST}

The authors declare that there are no conflicts of interest.

\section{ACKNOWLEDGMENT}

To Professor Dr. Rodrigo-Siqueira Baptista for his help in the idealization of the article.

\section{REFERENCES}

1. Almeida JD, Tyrrell DA. The morphology of three previously uncharacterized human respiratory viruses that grow in organ culture. J Gen Virol 1: 175-178, 1967.

2. Andersen KG, Rambaut A, Lipkin WI, Holmes EC, Garry RF. The proximal origin of SARSCoV-2. Nat Med 26: 450-452, 2020.

3. Buonaguro FM, Puzanov I, Ascierto PA. Anti-IL6R role in treatment of COVID-19-related ARDS. J Transl Med 18: 165, 2020.

4. Cao X. COVID-19: immunopathology and its implications for therapy. Nat Rev Immunol 20: 269-270, 2020a.

5. CDC. Centers for Disease Control and Prevention. Severe Acute Respiratory Syndrome (SARS) - April, 2004. Available in: <https://www.cdc.gov/sars/about/faq.html> Access in 10 may 2020.

6. Gasparyan AY, Misra DP, Yessirkepov M, Zimba O. Perspectives of Immune Therapy in Coronavirus Disease 2019. J Korean Med Sci 35: e176, 2020. 
7. Gharbharan A, Jordans C, Geurtsvankessel CH, Hollander JGD, Karim F, Mollema FPN, Stalenhoef-Schukken JE, Dofferhoff A, Ludwig I, Koster A, Hassing RJ, Bos JC, Pottelberge GRV, Vlasveld IN,Ammerlaan HSM, Leeuwen-Segarceanu EMV, Miedema J, Eerden MNVD, Papageorgiou G, Boekhorst PT, Swaneveld FH, Katsikis PD, Mueller Y, Okba NMA, Koopmans MPG, Haagmans BL, Rokx C, Rijnders B. 2020. Convalescent Plasma for COVID-19. A randomized clinical trial. Availiable in: $<$ https://www.researchgate.net/publication $/ 342882850$ Convalescent_Plasma_for_COVID-19_A_randomized_clinical_trial $>$ Access in: 21 dec 2020.

8. Giron CC, Laaksonen A, da Silva FLB. On the interactions of the receptor-binding domain of SARS-CoV-1 and SARS-CoV-2 spike proteins with monoclonal antibodies and the receptor ACE2. Virus Res 285: 198021, 2020.

9. Guan Y, Zheng BJ, He YQ, Liu XL, Zhuang ZX, Cheung CL, Luo SW, Li PH, Zhang LJ, Guan YJ, Butt KM, Wong KL, Chan KW, Lim W, Shortridge KF, Yuen KY, Peiris JSM, Poon LLM. Isolation and characterization of viruses related to the SARS coronavirus from animals in southern China. Science 302: 276-278, 2003.

10. Hamre D, Procknow JJ. Um novo vírus isolado do trato respiratório humano. Proc Soc Exp Biol Med 121: 190-193, 1966.

11. Kahn JS, McIntosh K. History and Recent Advances in Coronavirus Discovery. Pediatr Infect Dis J 24: S223-S227, 2005.

12. Li L, Zhang W, Hu Y, Tong X, Zheng S, Yang J, Kong Y, Ren L, Wei Q, Mei H, Hu C, Tao C, Yang R, Wang J, Yu Y, Guo Y, Wu X, Xu Z, Zeng L, Xiong N, Chen L, Wang J, Man N, Liu Y, Xu H, Deng E, Zhang X, Li C, Wang C, Su S, Zhang L, Wang J, Wu Y, Liu Z. Effect of Convalescent Plasma Therapy on Time to Clinical Improvement in Patients With Severe and Life-threatening COVID-19: A Randomized Clinical Trial. JAMA 324: 460-470, 2020.

13. Lundstrom K. Coronavirus Pandemic-Therapy and Vaccines. Biomedicines 8: E109, 2020.

14. Ruklanthi de Alwis, Shiwei Chen, Esther S. Gan, Eng Eong Ooi. Impact of immune enhancement on Covid-19 polyclonal hyperimmune globulin therapy and vaccine development. EBioMedicine 55, 102768, 2020, doi: 10.1016/j.ebiom.2020.102768.

15. Savoy ML. Manuals MSD. 2018. Avaliable at: <https://www.msdmanuals.com/pt/profissional/ doen $\% \mathrm{C} 3 \% \mathrm{~A} 7$ asinfecciosas/imuniza $\% \mathrm{C} 3 \% \mathrm{~A} 7 \% \mathrm{C} 3 \% \mathrm{~A} 3 \mathrm{o} /$ imuniza $\% \mathrm{C} 3 \% \mathrm{~A} 7 \% \mathrm{C} 3 \% \mathrm{~A} 3 \mathrm{o}-$ passiva\#v12817762_pt> Access in 10 may 2020.

16. Shaffer L. 15 drugs being tested to treat COVID-19 and how they would work. Nature, 2020. Avaliable at $<$ https://www.nature.com/articles/d41591-020-00019-9>>. Accesss in 15 may 2020.

17. Shanmugaraj B, Siriwattananon K, Wangkanont K, Phoolcharoen W. Perspectives on monoclonal antibody therapy as potential therapeutic intervention for Coronavirus disease-19 (COVID-19). Asian Pac J Allergy Immunol 38: 10-18, 2020.

18. Tian X, Li C, Huang A, Xia S, Lu S, Shi Z, Lu L, Jiang S, Yang Z, Wu Y, Ying T. Potent binding of 2019 novel coronavirus spike protein by a SARS coronavirus-specific human monoclonal antibody. Emerg Microbes Infect 9: 382-385, 2020.

19. Wang C, Li W, Drabek D, Okba NMA, van Haperen R, Osterhaus ADME, van Kuppeveld FJM, Haagmans BL, Grosveld F, Bosch BJ. A human monoclonal antibody blocking SARS-CoV-2 infection. Nat Commun 11: 2251, 2020.

20. WHO. World Health Organization. Middle East respiratory syndrome coronavirus (MERS-CoV). 2020a. Avaliable at: < https://www.who.int/health-topics/middle-east-respiratory-syndromecoronavirus-mers\#tab=tab_1 > Access in 10 may 2020.

21. WHO. World Health Organization. Report of the WHO-China Joint Mission on Coronavirus Disease 2019 (COVID-19). 2020b. Avaliable at: https://www.who.int/docs/default-source/ coronaviruse/who-china-joint-mission-on-covid-19-final-report.pdf > Access in 16 feb 2020.

22. Zhao M. Cytokine storm and immunomodulatory therapy in COVID-19: Role of chloroquine and anti-IL-6 monoclonal antibodies. Int J Antimicrob Agents 55: 105982, 2020. 